\title{
Analysis of elastic buckling behavior of steel delta girders
}

\author{
Mohammadali Jafari Sahnehsaraei $^{1}$, Saeed Erfani ${ }^{2}$ \\ ${ }^{I}$ PhD, Faculty of Engineering, Islamic Azad University, South Tehran Branch, Tehran, Iran \\ ${ }^{2}$ MSc, Faculty of Engineering, Islamic Azad University, South Tehran Branch, Tehran, Iran \\ *Corresponding author_E-mail: erfani_s.5475@yahoo.com
}

Copyright $\odot 2014$ Mohammadali Jafari Sahnehsaraei, Saeed Erfani. This is an open access article distributed under the Creative Commons Attribution License, which permits unrestricted use, distribution, and reproduction in any medium, provided the original work is properly cited.

\begin{abstract}
Given the widespread use of beam and plate in structures, it is essential to have a thorough understanding of girder behavior. According to buckling failure mode in plates, it is necessary to take measures in this regard. Delta stiffener is using this approach. Due to the lack of technical knowledge about these kinds of plate beam, it is necessary to find good geometric properties of the delta girder plates for both technically and economically optimization. Therefore, in this paper, by modeling and finite element analysis for simple girder (without Stiffener), beam hardening by longitudinal plate and beam using delta hardening behavior are examined under the effect of the bending moment. Finite element analysis of elastic buckling analysis is included. With the above analysis, the effect of longitudinal stiffener and Delta Girders in terms of economic considerations has been studied.
\end{abstract}

Keywords: Elastic Buckling, Beam, Plate, Stiffener.

\section{Introduction}

By increase in span length, thus increasing the amount of bending moment, it seems that the rolled profiles on the market do not provide the required forces and bending moment's capacity.

The important issue to be investigated is the buckling in plated of girders. A metal plate bearing capacity can be increased by the following factors [1], [2].

1) Increase in thickness, which reduces the amount of plates buckling.

2) Put some proper stiffeners, increasing the flexural stiffness of the steel plate steel plate.

Stiffeners are structural components that are connected by a steel plate, are going corner welds. Initial distortion, buckling under the plates when the object is located external to the crowd, will accelerate. Hard Manufacturer They is usually placed in two directions perpendicular to each other [3], [4].

Stiffener Longitudinal to deal with the moment, are in the area, pressure plate. Stiffener the transverse shear buckling resistance for increased substantially, are considered.[5], [6] The plates by strengthening the longitudinal stiffener often bridges and bending forces to deal with the need to cease from the following institutions within which they are used. What's so hard being the length of the diagonal of the face of the die is attached to the wing of the resulting plate or plate of the Delta are very unhealthy [7].

\section{Modeling assumptions}

Then the modeling process is done in this paper. In Continues, the geometry is depicted. The base model beam height is $100 \mathrm{~cm}$, width $50 \mathrm{~cm}$, thickness of the wing is equal to $1 \mathrm{~cm}$. for each model by changing the geometric parameters, the values of buckling capacity has been calculated. 


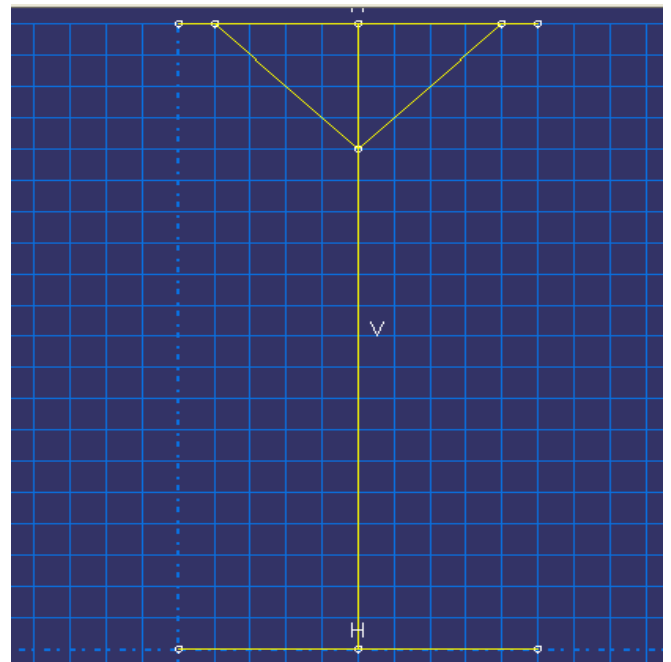

Fig. 1: Geometry Beam Length is Assumed 1.5 Meters, and Has Rigid Connection on One Side.

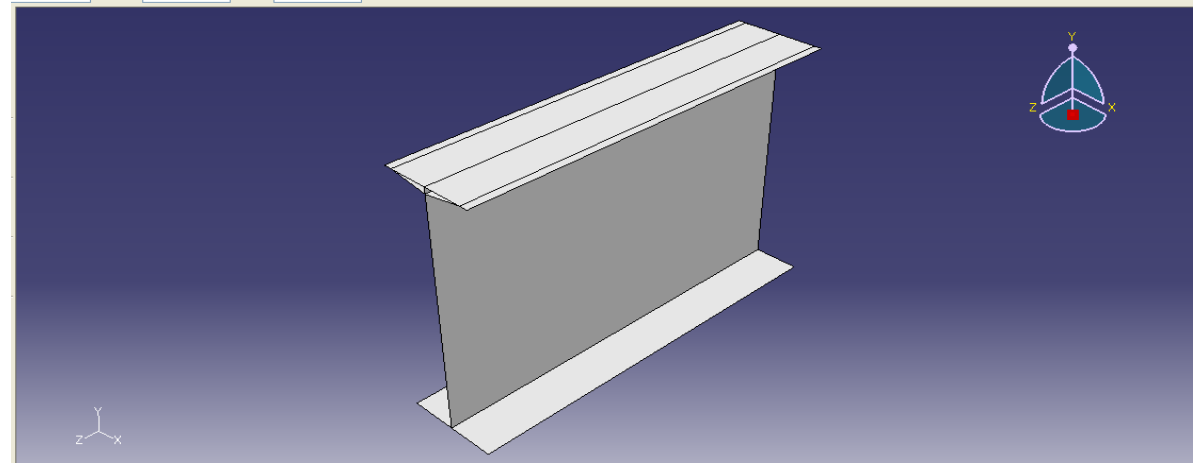

Fig. 2: Three-Dimensional Model in ABAQUS Software

The final geometry model is shown in the figure above. The elastic modulus is $\mathbf{2 E 5} \mathbf{~ k g} / \mathbf{c m}^{2}$ and Poisson's ratio equal to 0.3 . The plate density is equal to $0 \mathbf{~ k g} / \mathbf{m}^{3}$.

\section{Analysis of changes in the height of the beam plate models}

This section summarizes and compares the models simple plate beam, beam longitudinal stiffener plate delta and July will be reviewed. These models are respectively called H-NS, H and H-LS are named. The following table summarizes the results of these three models is presented.

Table 1: Summary of Flexural Buckling Resistance of the Plate Beam Altitude Change Models

\begin{tabular}{cccc}
\hline & \multicolumn{3}{c}{ Flexural buckling strength } \\
\hline H-LS & H-NS & H & $(\mathrm{cm})$ Beam height \\
971.9 & 972.3 & 1008.3 & 60 \\
1308.7 & 1333.3 & 1364.1 & 80 \\
1682.5 & 1712.6 & 1747.2 & 100 \\
2071.1 & 2100.4 & 2137.1 & 120 \\
\hline
\end{tabular}




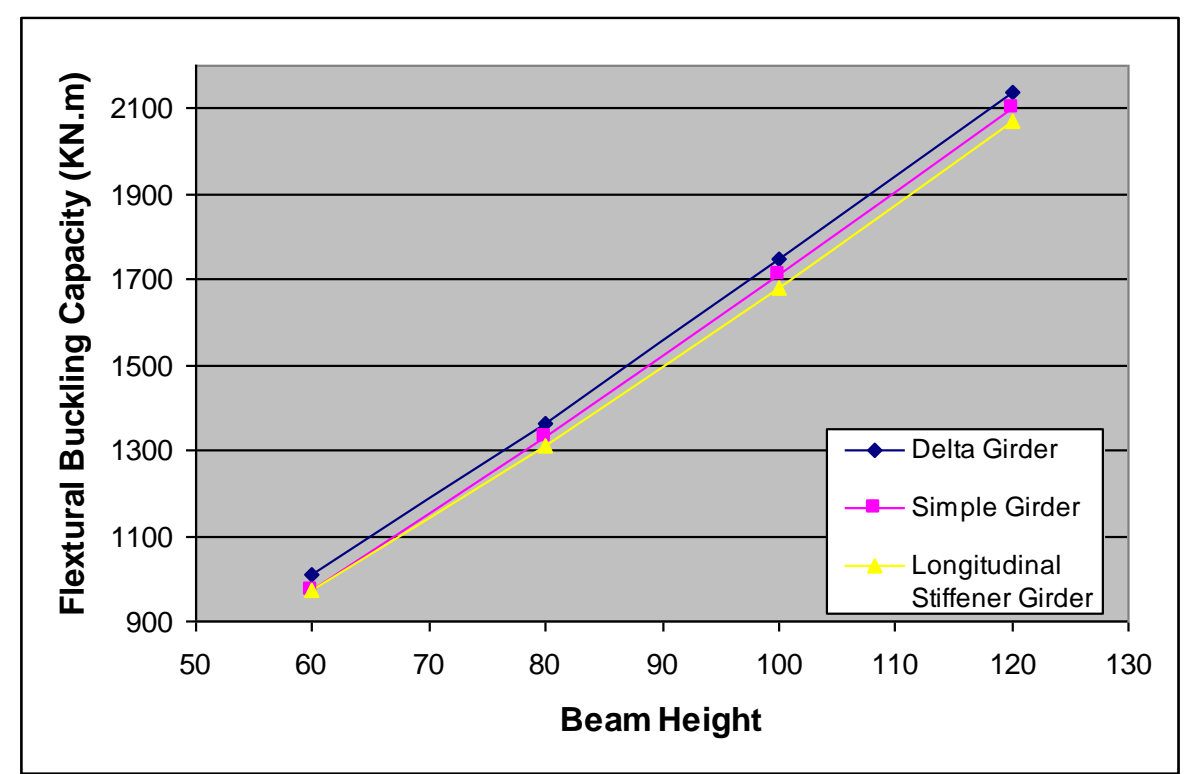

Fig. 3: Comparison of Buckling Strength of Plate Bending Beam Altitude Change Models

On chart review to compare the results of flexural buckling resistance of plate models can be seen that the change in beam height beam flexural buckling resistance of plate delta in all the cases up. However, this may not be significant and greater resistance variation is approximately $1 \%$. In fact, based on these results, it seems that adding the Stiffener has no significant impact on Girder resistance. Seems to result from an elastic buckling analysis and performance analysis for failing to obtain the real strength is Girder.

Table 2: Summary of Shear Buckling Resistance of the Plate Beam Altitude Change Models

\begin{tabular}{cccc}
\hline & Shear buckling strength & \\
\hline H-LS & H-NS & H & (cm)Beam height \\
1048.7 & 1045 & 1109.8 & 80 \\
1403.5 & 1398.7 & 1485.5 & 100 \\
1680.7 & 1590.8 & 1745.8 & 120 \\
1661 & 1557.1 & 1709.4 & 00 \\
\hline
\end{tabular}

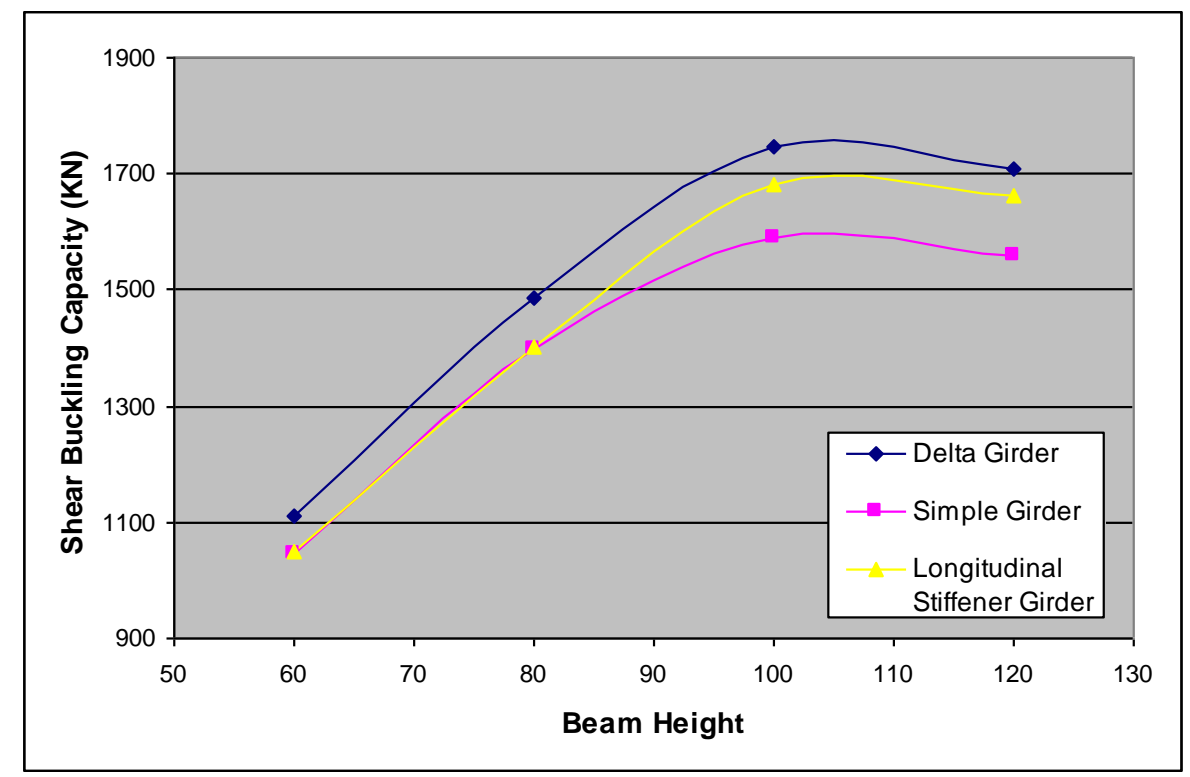

Fig. 4: Comparison of Shear Buckling Resistance of Plate Models the Change in Beam Height

Shear buckling resistance of the reviews comparison chart plate can be seen that models the change in beam height beam shear strength than Delta Plate simple plate beam plate beam models with longitudinal stiffener is. The dispute is between $6 \%$ to $10 \%$. Therefore, the beam shear behavior of plate delta has better performance. 


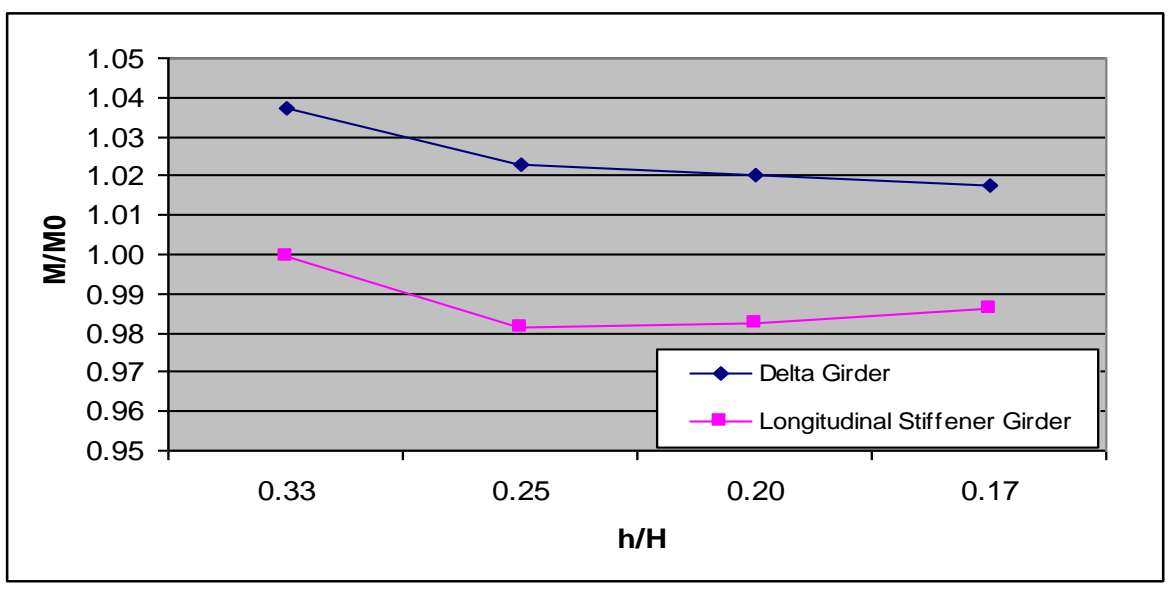

Fig. 5: Changes in the Ratio $M / M_{0}$ versus the Ratio $H / H$

In the diagram above the tolerable levels for beam buckling flexural strength of the longitudinal stiffener plate anchor tolerable than a simple plate to keep the geometry of the beam relative to the geometry of parameter variations on $\mathrm{h} / \mathrm{H}$ investigated.

According to the graph it can be seen that the flexural capacity of the beam longitudinal stiffener plates with different ratios $\mathrm{h} / \mathrm{H}$ less than a simple plate beam, and the beam plate beam plate delta is less simple. Also, the ratio of 0.33 , which is equivalent to 60 centimeters in height, delta plate beam flexural capacity of more shows.

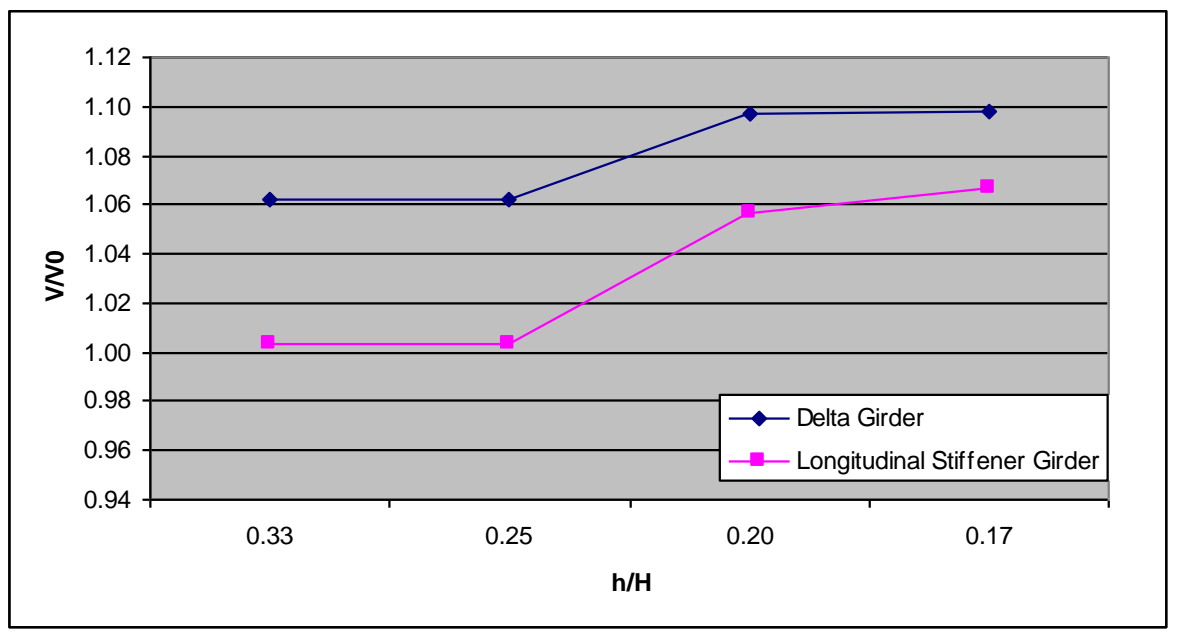

Fig.6: Changes in the Ratio $\mathrm{V} / \mathrm{V}_{0}$ in Terms of the Ratio $\mathrm{H} / \mathrm{H}$

In the diagram above the tolerable levels for the beam shear buckling of plates with longitudinal stiffener anchor tolerable than a simple plate to keep the geometry of the beam relative to the geometry of parameter variations on $\mathrm{h} / \mathrm{H}$ investigated. According to the chart, we can see that the ratio h / $\mathrm{H}$, the beam height, plate, plate shear buckling beam length and beam than a simple plate metal crossbar Delta also has the best performance.

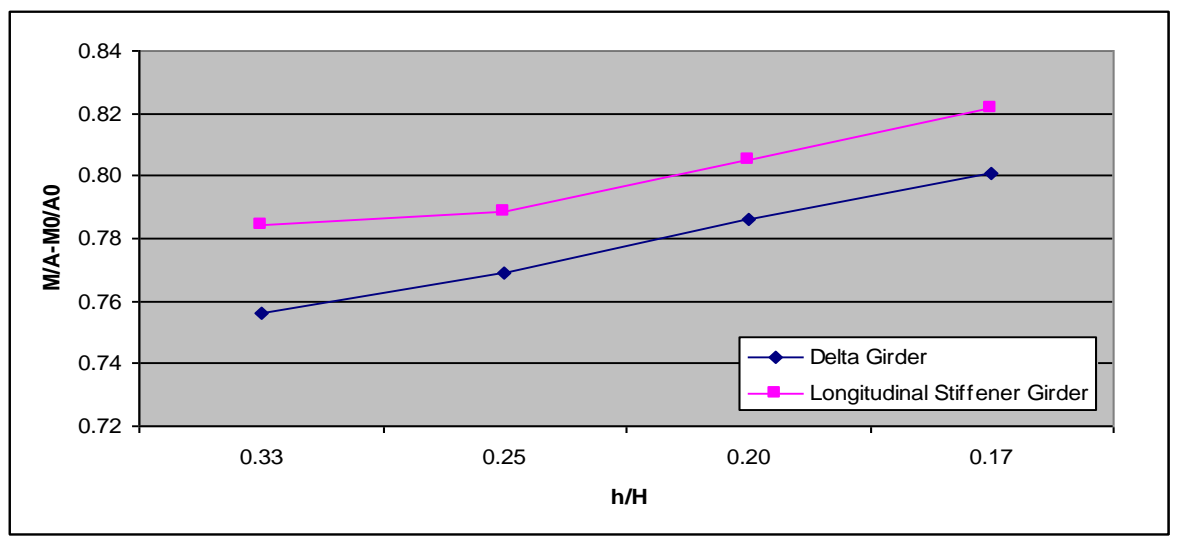

Fig. 7: Change the Ratio M/A-M $\mathrm{M}_{0} / \mathrm{A}_{0}$ Based on the Ratio $\mathrm{H} / \mathrm{H}$ 
In the above diagram, the bending buckling loads tolerated by the area parameter for longitudinal beam hardening plate anchor tolerable than simply preserving the geometric characteristics of the shooting plate relative to the geometry of parameter variations on $\mathrm{h} / \mathrm{H}$ investigated.

According to the diagrams show a decreased ratio h / $\mathrm{H}$ leads to beam flexural buckling resistance of plate upside down with regard to the economic parameters (surface area) is. So whatever the ratio h / $\mathrm{H}$ is smaller than the buckling loads shooting plate Lhat more resistant to bending and is more economical.

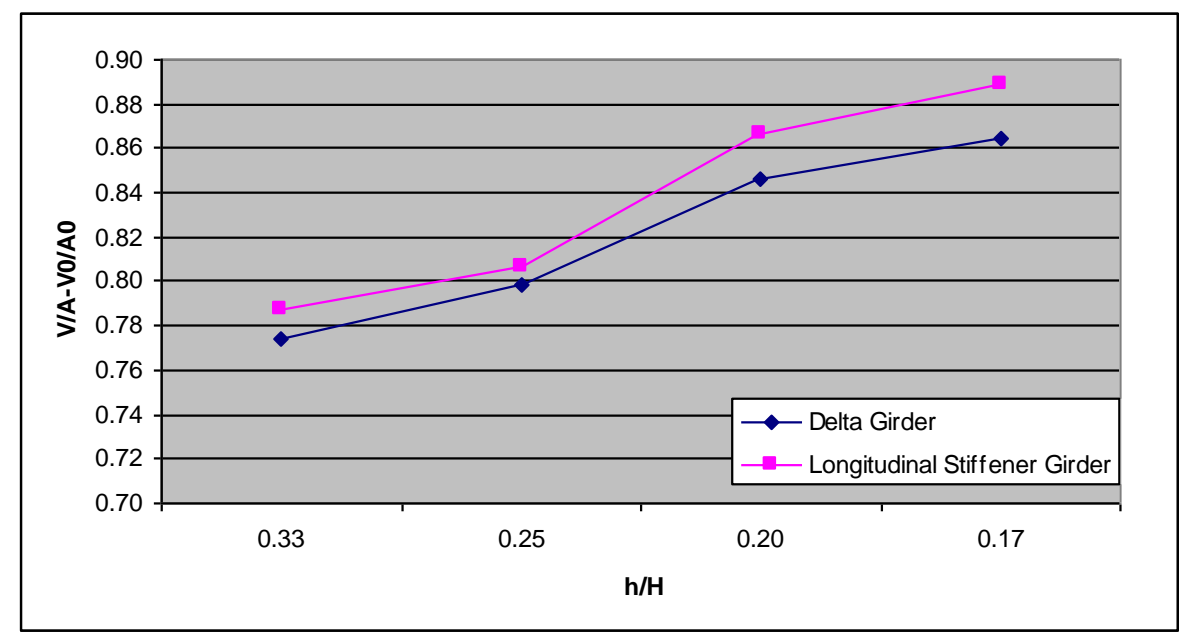

Fig. 8: Changes in the Ratio V/A- $\mathrm{V}_{0} / \mathrm{A}_{0}$ in Terms of the Ratio $\mathrm{H} / \mathrm{H}$

In the diagram above a tolerable level shear buckling based on the parameters related to the shooting area of the plate with a longitudinal stiffener plate for beam tolerable than simply maintaining the geometry of the anchor relative to the geometry of parameter variations on $\mathrm{h} / \mathrm{H}$ investigated.

According to the diagrams show a decreased ratio h / $\mathrm{H}$ leads to beam shear buckling resistance of plate upside down with regard to the economic parameters (surface area) is. So whatever the ratio $\mathrm{h} / \mathrm{H}$ is smaller shot charge plate against shear buckling Lhat is more resistant and more economical.

\section{Summary}

This section summarizes the results of analyzes based on elastic buckling mode, the optimum ratio of geometrical cross section (the sections examined under the target load) based on the flexure and shear capacity would be introduced in Economic Parameters. It can be restated as follows:

The ratio $\mathrm{h} / \mathrm{H}$ is smaller than the buckling loads shooting plate Lhat more resistant to bending and is more economical. Delta beam hardening plate with the ratio b / B equals 09, which is equivalent to assuming a height of $100 \mathrm{~cm}$ width 65 $\mathrm{cm}$ has wings; it will show the greatest resistance to bending.

With the increase of T S / T f increasing the thickness of the stiffener to the beam flange thickness of plate resistance is found to be better flexural buckling. Ratio of approximately 0.25 and 0.75 times the flexural strength values, so the ratio of 0.25 for $\mathrm{T} \mathrm{S} \mathrm{/} \mathrm{T} f$ is more desirable.

So what criteria and economic analysis are considered, leading to increased resistance to bending buckling beam plate thickness increases the life of the delta. Also in July, Delta plate ratios Ts / Tw Greater than 0.5, the shear strength is almost constant.

By increasing the ratio $\mathrm{h} / \mathrm{b}$ for beam flexural buckling resistance of plate delta ratio decreases. Therefore, assuming constant parameter $\mathrm{b}$, height tough delta contributes to decreased resistance to flexural buckling.

\section{Conclusions}

Elastic buckling analysis (Eigen values) is not able to calculate critical buckling load for a certain direction of certain moment (positive or negative). Thus, adding a stiffener results in buckling mode variation and does not provide a significant increase in relevant critical load value. Therefore, based on these values adding a stiffener seem not economic which is not logical. Finally, it is necessary to provide inelastic behavior using plastic behavior of section and considering large deformation as well, which will be illustrated on future papers by authors. 


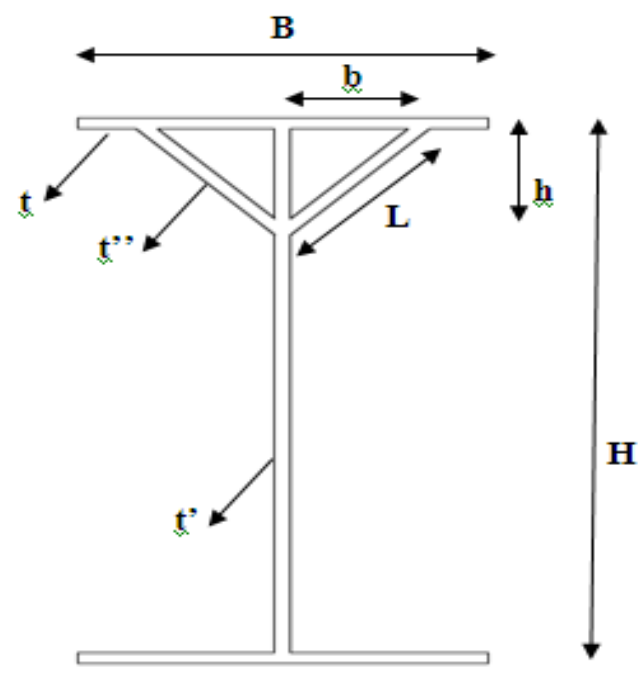

Fig. 9: View of Model Parameters

Table 3: Dimensions in Optimum Level

\begin{tabular}{ll}
\hline Parameter & Value \\
\hline$\alpha$ & 45 degree \\
B & $65 \mathrm{~cm}$ \\
$\mathrm{H}$ & $100 \mathrm{~cm}$ \\
$\mathrm{~b}$ & $29 \mathrm{~cm}$ \\
$\mathrm{~h}$ & $29 \mathrm{~cm}$ \\
$\mathrm{t}$ & $2 \mathrm{~cm}$ \\
t' & $1 \mathrm{~cm}$ \\
t', & $0.5 \mathrm{~cm}$ \\
\hline
\end{tabular}

\section{References}

[1] Rhodes. J, Some observations on the post-buckling behavior of thin plates and thin-walled members, Thin-Walled Structures, Volume 41, Issues 2-3, February 2003, Pages 207-226.

[2] Bakker, M.C.M, Rosmanit, M and Hofmeyer, H, Prediction of the elasto-plastic post-buckling strength of uniformly compressed plates from the fictitious elastic strain at failure, Thin-Walled Structures, Volume 47, Issue 1, January 2009, Pages 1-13 http://dx.doi.org/10.1016/j.tws.2008.04.004.

[3] Rhodes, J, Buckling of thin plates and members - and early work on rectangular tubes, Thin-Walled Structures, Volume 40, Issue 2, February 2002, Pages 87-108 http://dx.doi.org/10.1016/S0263-8231(01)00054-4.

[4] Herzl Chai, Contact buckling and post buckling of thin rectangular plates, Journal of the Mechanics and Physics of Solids, Volume 49, Issue 2, February 2001, Pages 209-230 http://dx.doi.org/10.1016/S0022-5096(00)00038-7.

[5] Shahabad, F and Roberts, T. M., Buckling of slender web plates subjected to combinations of in-plane loading, Journal of Constructional Steel Research, Volume 51, Issue 2, August 1999, Pages 99-121 http://dx.doi.org/10.1016/S0143-974X(99)00020-6.

[6] C. M. Wang, Y. Chen and Y. Xiang, Plastic buckling of rectangular plates subjected to intermediate and end in plane loads, International Journal of Solids and Structures, Volume 41, Issues 16-17, August 2004, Pages 4279-4297.

[7] Danielson and, D. A., Wilmer, A., Buckling of stiffened plates with bulb flat flanges, International Journal of Solids and Structures, Volume 41, Issues 22-23, November 2004, Pages 6407-6427. 